\section{Ileal Ascariasis Detected by Magnified Terminal Ileoscopy}

\author{
A. Trecca ${ }^{1}$, F. Gaj ${ }^{2}$, S. Serafini ${ }^{1}$, \\ M. Sperone ${ }^{1}$ \\ ${ }^{1}$ Operative Units of Endoscopy and \\ Gastroenterology "Fabio Di \\ Giovambattista”, Rome, Italy \\ 2 Department of General Surgery, Second \\ Surgical Clinic, University of Rome \\ “La Sapienza”, Rome, Italy
}

\section{Corresponding Author}

A. Trecca, M. D.

Operative Units of Endoscopy and Gastroenterology "Fabio Di Giovambattista“

Via Reno, 30

00198 Rome

Italy

Fax: + 39-06-8689-7737

E-mail: arimecme@tin.it

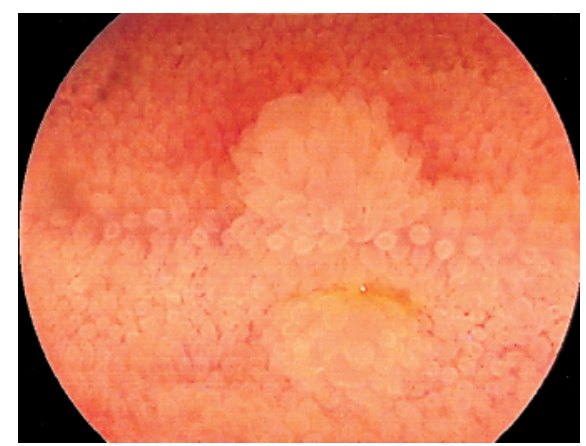

Figure 1 A 45-year-old Peruvian nun was referred to us for investigation of severe weight loss (more than $9 \mathrm{~kg}$ in 1 week) and asthenia. Esophagogastroduodenoscopy and total colonoscopy were negative, but terminal ileoscopy revealed an isolated finding of an enlarged submucosal follicle.

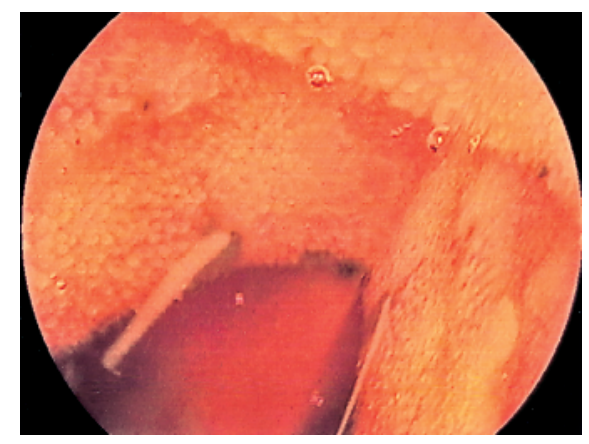

Figure 2 A biopsy was performed and suddenly two white worms became apparent.The view of the terminal ileum obtained using the Fujinon EC-410 CM magnifying colonoscope (Fujinon Co., Omiya, Japan) made it possible to biopsy one of the worms, and histological investigation revealed ileal ascariasis. The patient underwent substantial antibiotic therapy with a complete remission of weight loss and anemia within one week 